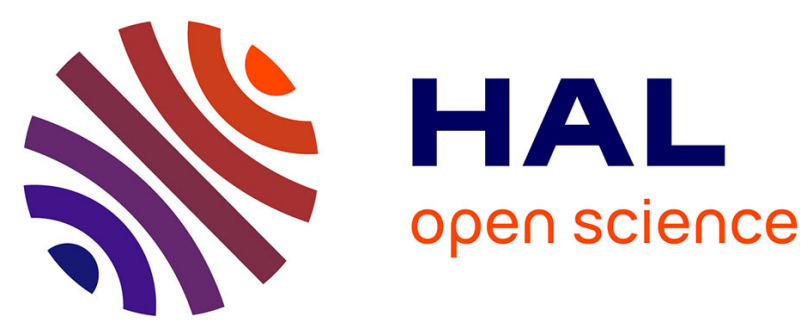

\title{
Evaluation of a hybrid anaerobic biofilm reactor treating winery effluents and using grape stalks as biofilm carrier
}

Mohamed Ali Wahab, Frédéric Habouzit, Nicolas Bernet, Naceur Jedidi, Renaud R. Escudie

\section{- To cite this version:}

Mohamed Ali Wahab, Frédéric Habouzit, Nicolas Bernet, Naceur Jedidi, Renaud R. Escudie. Evaluation of a hybrid anaerobic biofilm reactor treating winery effluents and using grape stalks as biofilm carrier. Environmental Technology, 2016, 37 (13), pp.1676-1682. 10.1080/09593330.2015.1127291 . hal-02636124

\section{HAL Id: hal-02636124 \\ https://hal.inrae.fr/hal-02636124}

Submitted on 27 May 2020

HAL is a multi-disciplinary open access archive for the deposit and dissemination of scientific research documents, whether they are published or not. The documents may come from teaching and research institutions in France or abroad, or from public or private research centers.
L'archive ouverte pluridisciplinaire HAL, est destinée au dépôt et à la diffusion de documents scientifiques de niveau recherche, publiés ou non, émanant des établissements d'enseignement et de recherche français ou étrangers, des laboratoires publics ou privés. 


\section{Evaluation of a hybrid anaerobic biofilm reactor treating winery effluents and using grape stalks as biofilm carrier}

\section{Mohamed Ali Wahab, Frédéric Habouzit, Nicolas Bernet, Naceur Jedidi \& Renaud Escudié}

To cite this article: Mohamed Ali Wahab, Frédéric Habouzit, Nicolas Bernet, Naceur Jedidi \& Renaud Escudié (2015): Evaluation of a hybrid anaerobic biofilm reactor treating winery effluents and using grape stalks as biofilm carrier, Environmental Technology, DOI: 10.1080/09593330.2015.1127291

To link to this article: http://dx.doi.org/10.1080/09593330.2015.1127291

Accepted author version posted online: 10

Dec 2015.

Submit your article to this journal $₫$

View related articles

View Crossmark data $ک$ 
Publisher: Taylor \& Francis

Journal: Environmental Technology

DOI: $10.1080 / 09593330.2015 .1127291$

\title{
Evaluation of a hybrid anaerobic biofilm reactor treating
}

\section{winery effluents and using grape stalks as biofilm carrier}

\section{Mohamed Ali Wahab ${ }^{a, b}$, Frédéric Habouzit ${ }^{b}$, Nicolas Bernet ${ }^{b}$, Naceur}

\author{
Jedidia ${ }^{a}$ Renaud Escudiéb
}

\begin{abstract}
${ }^{a}$ Université de Carthage, Centre de Recherche et des Technologies des Eaux, Laboratoire de Traitement et de Valorisation des Rejets Hydriques, BP. 273, 8020 Soliman, Tunisie. Email : wahab med@yahoo.fr, naceur.jedidi@certe.rnrt.tn
\end{abstract}

b INRA, UR050, Laboratoire de Biotechnologie de l'Environnement, Avenue des Etangs, Narbonne F-11100, France. email : habouzit@supagro.inra.fr, bernet@s,supagro.inra.fr, escudie@supagro.inra.fr

\section{Abstract}

Wine production processes generate large amount of both winery wastewater and solid wastes. Furthermore, working periods, volumes and pollution loads greatly vary over the year. Therefore, it is recommended to develop a low cost treatment technology for the treatment of winery effluents taking into account the variation of the organic loading rate (OLR). Accordingly, we have investigated the sequential operation of an anaerobic biofilm reactor treating winery effluents and using grape stalks as biofilm carrier with an OLR ranging from 0.65 to $27 \mathrm{gCOD} / \mathrm{L} / \mathrm{d}$. The result showed that, during the start-up with wastewater influent, the 
COD removal rate ranged from 83 to $93 \%$ and was about $91 \%$ at the end of the start-up period that lasted for 40 days. After three months of inactivity period of the reactor (no influent feeding), we have succeeded in restarting-up the reactor in only 15 days with a COD removal of $82 \%$ and a low concentration of volatile fatty acids $(1 \mathrm{~g} / \mathrm{L})$, which confirms the robustness of the reactor. As a consequence, Grape stalks can be used as an efficient carrier support, allowing a fast reactor start-up while the biofilm conserves its activity during a non-feeding period. The proposed hybrid reactor thus permits to treat both winery effluents and grape stalks.

\section{Keywords}

anaerobic digestion; biofilm reactor; grape stalks; start-up, winery effluent. 


\section{Introduction}

Viticulture and winery industry are two important economic activities in Mediterranean areas and their importance is in growing increase in other parts of the world. [1,2] Consequently, vineyard is considered as one of the largest consumer of both water and agrochemicals such as chemical fertilizer, and wineries also consume large quantities of water and energy. Furthermore, increased production in these two sectors has been always coupled with many economic and environmental problems due to the generation of large amount of wastewater and solid waste often discarded with little or no treatment due to the hightreatment costs. The discharge of these wastes in the environment causes many problems to water bodies, such as eutrophication and other adverse environmental effects such as soil salinization and sodicity, contamination of groundwater, waterlogging and anaerobiosis. [3] Moreover, increase of production in wineries is related to an increase of their carbon footprint and their operating expenses due to the use of fossil fuel as source of energy. Thus, wineries had to focus on improving energy efficiency, water use and wastewater management by developing a low cost sustainable technology for the treatment and recycling of their wastes.

Winery wastewater production is inevitable, achieving values from 3000 to $5000 \mathrm{~L} /$ ton of grapes crushed [4], resulting essentially from product loss and many different cleaning operations, with singular characteristics depending on process activities. [5] In general, a typical raw winery wastewater presents a $\mathrm{pH}$ between 3 and 4, a chemical oxygen demand (COD) from 0.5 to $45 \mathrm{gO} 2 / \mathrm{L}$ and total suspended solids (TSS) from 0.012 to $7.3 \mathrm{~g} / \mathrm{L}$, while biological oxygen demand (BOD5) is about $0.4-0.9$ of the COD value. [5,6] The high biodegradability of winery wastewater often justifies the choice of conventional biological treatments. [7,8] Among all the available biological treatment technologies, anaerobic digestion $(\mathrm{AD})$ is one of the most adequate one for the treatment of wastewater having high organic carbon concentration such as winery effluents, because it allows the agronomic and 
energetic recycling of organic wastes. In fact, during the AD processes, biodegradable organic matters are converted into biogas that can be used as a clean renewable energy instead of fossil fuels, while the non-biodegradable organic fraction remains in the digestate which is rich in nutrients and can be used as a biofertilizer in place of chemical fertilizer.

Many configurations of $\mathrm{AD}$ have been developed for the treatment of both wastewater and solid waste, among which, anaerobic fixed bed reactor offers an interesting advantage for the treatment of wastewater with high concentration of readily biodegradable COD and high organic loads [8-11] In this system, microorganisms grow on the surface of carriers with a high void ratio to form an active biofilm. However, the high plastic carrier costs makes the implementation of such reactor on-site very expensive for the small winery industries.

Furthermore, the seasonal nature of winery industries raises specific problems for the treatment processes in terms of wastewater volume and composition. [12-14] Consequently, the treatment system must be versatile to face both the high organic loading for relatively short periods during harvesting and vintage, and the stream fluctuation. Furthermore, an appropriate treatment system has to achieve successions of start-up and shut-down operations, including periods of inactiyity. [7,15]

Different natural and artificial solid materials can be used as biofilm carriers. Commercial carrier supports which are usually made of polyethylene, polypropylene or polyurethane, are expensive, while natural carriers are essentially inorganic such as sand, gravel, pumice stone, porous glass beads and zeolite. [16] The efficiency of lignocellulosic materials to be used as biofilm carrier has not been well studied. [17,18] Accordingly, in the present study, we propose to develop a new anaerobic biofilm reactor operated sequentially and using grape stalk (GS) as a carrier support displace to plastic support in order to reduce treatment costs and to response to the seasonal nature of winery industries. In fact, GS are the skeleton of the grape bunch and consist in lignified tissues. [19] The inherent recalcitrance of these 
lignocellulosic biomasses towards enzymatic and microbial deconstruction makes their use as carrier support possible. Furthermore, the accumulation of these biomass residues in industrial plants, besides occupying space, usually attracts insects and rodents. [20] Thus, the upgrading of this by-product through using them as support carrier can entail economic and environmental improvements for the industry.

The aims of this study was to investigate the efficiency of using GS as biofilm carrier for the development of biofilm in anaerobic fixed bed reactor during both the start-upperiod and the restart-up after a long period of inactivity. The final goal is to propose a hybrid reactor permitting to treating both winery effluents and grape stalks. This hybrid reactor is a combination of fixed bed reactor for the treatment of the effluent and solid digester for the treatment of solid waste. This treatment (liquid-solid) could be made simultaneously or sequentially.

\section{Materials and Methods}

\section{Experimental set-up}

The anaerobic fixed bed reactor used in this study is a PVC column with an internal diameter of $0.20 \mathrm{~m}$ and a height of $0.56 \mathrm{~m}$. [10] The total and working volumes of the reactor were 16.7 $\mathrm{L}$ and $14.8 \mathrm{~L}$, respectively. The reactor was operated under mesophilic condition with a temperature of $35^{\circ} \mathrm{C}$. The reactor was packed with about $1 \mathrm{~kg}$ of GS used as a carrier support for biomass immobilization and retention. The physico-chemical characteristics of GS used in this study are given in Table1. The feed wastewater was pumped into the bottom of the reactor by means of a peristaltic pump. The reactor liquid was homogenized with immersed pump at the rate of $66 \mathrm{~L} / \mathrm{min}$. The effluent was discharged at the top through a U-tube for separation of gas. $\mathrm{pH}$ was measured in the liquid outlet with a Mettler Toledo 1100 Calimatic 
$\mathrm{pH}$ meter, regulated at 6.8 by automatic $\mathrm{NaOH}$ addition. Biogas produced passed through a moisture trap and then to a milligas counter fitted with a 4-20 mA output (MGC-1 gas flow meters, Ritter).

[Table 1 near here]

\section{Influent preparation and reactor inoculation}

A synthetic winery wastewater was daily prepared by diluting red wine to obtain different COD ranging from 0.5 to $24 \mathrm{~g} / \mathrm{L}$. The feed was supplemented with nutrients to obtain a $\mathrm{COD} / \mathrm{N} / \mathrm{P}$ ratio of $400 / 7 / 1 .[21,22]$

The sludge was sampled in a large-scale anaerobic reactor treating distillery vinasse. The reactor was inoculated with 1 gram of volatile solid per liter $\left(\mathrm{gvs}_{\mathrm{v}} / \mathrm{L}\right)$ of this sludge with a specific COD removal rate of 0.64 gCoDremoved/gvss, measured using ethanol as a substrate. [23] The protocol used is based on the works of Cresson et al. showing the competition between planktonic and fixed microorganisms. [9] The efficiency of this start-up strategy has been demonstrated for fixed bed reactors. [24]

\section{Reactor operation}

The reactor was operated sequentially during 146 days in three phases to investigate its efficiency to be started up rapidly and restarted after a non-feeding period. During the first 40 days, after the inoculation phase, the reactor was fed continuously, starting at a low OLR of $0.65 \mathrm{gCOD} / \mathrm{L} . \mathrm{d}$ and a short hydraulic retention time (HRT) of $18 \mathrm{~h}$ to wash out the planktonic micro-organisms and thus favour biofilm formation. [9] When $80 \%$ of COD removal was reached, OLR was daily increased by $15 \%$ till an OLR of 24 gCOD/L.d at the same HRT (18h). [25] This maximal OLR has been maintained for 5 days to investigate the reactor stability. At the end of these 40 days, the reactor feeding was stopped for three months. After this period 
of inactivity, the reactor was fed again at an initial OLR of 2 gCoD/L.d. OLR was increased daily by $15 \%$ till reaching the OLR of $27 \mathrm{gCOD} / \mathrm{L} . \mathrm{d}$ within a period of 15 days.

\section{Physico-chemical analyses}

Total suspended solids (TSS), volatile suspended solids (VSS) and Chemical Oxygen Demand (COD) were analysed according to Standard Methods for examination of water and wastewater (APHA, 1992). [26] VFA were measured with a flame ionization detector gas chromatograph Varion 3900. The column was a semi capillary Econocap FFAP. The temperature of the oven was programmed to rise from $80{ }^{\circ} \mathrm{C}$ to $120^{\circ} \mathrm{C}$ with an increment of $10^{\circ}$ C.min-1. The biogas composition was analysed by gas chromatography (Shimadzu GC 8A) equipped with a CTRI Alltech column. Detection was performed with a thermal conductivity detector. The measurement of $\mathrm{CO}_{2}$ and $\mathrm{CH}_{4}$ was allowed by an internal calibration. Argon was used as the carrier gas.

\section{Results and discussion}

The anaerobic biofilm reactor treating winery effluent and using GS as a carrier support was operated over 146 days divided into three phases; two phases of start-up separated by a phase of three months of inactivity (no reactor feeding)

\section{Start-up period}

The objective of the first phase was to investigate the possibility of using GS as a biofilm carrier in anaerobic biofilm reactors. This was done by studying the efficiency of the reactor to be started up in a short period. Fig. 1 presents the OLR and the associated COD removal rate throughout this period. According to the start-up strategy, the carbon removal rate must 
reach $80 \%$ before increasing the OLR after the inoculation step. [9] Thus the reactor was operated initially during the first week at a low OLR of 0.6 gCoD/L.d until reaching a removal efficiency of about $82 \%$. This period of one week, considered as the acclimation phase, was quite rapid and related to the type of wastewater treated (ethanol, which is readily biodegradable, and the primary constituent of winery wastewater). [8] From the $7^{\text {th }}$ day and over the next 24 days, the OLR was increased progressively by $15 \%$ daily. During this startup period, the COD removal increased from $82 \%$ to $93 \%$ in two weeks. Then, from an OLR of 7 to $24 \mathrm{gCOD} / \mathrm{L} . \mathrm{d}$, the COD removal remained almost constant at about $92 \%$. At the end of the start-up period, the OLR was kept constant ( 24 gCOD/L.d) for 5 days during which the COD removal remained constant, which indicated a stability of the reactor. During the startup period, the COD from mineralization of grape stalk could be considered as negligible due to their low biodegradability and the high COD concentration of the synthetic winery wastewater.

\section{[Figure 1 near here]}

In order to understand the hydrolytic and the methanogenic activities of the biofilm during the start-up, the VFA concentrations were determined daily. Fig.2 presents the variation of VFA concentrations throughout the start-up period: VFA accumulation can be divided in three steps. The first step of one week is attributed to the acclimation phase during which microorganisms of the inoculum started to use the ethanol from the influent as a substrate. During this phase, the VFA concentration which was initially at about $0.43 \mathrm{~g} / \mathrm{L}$ started to decrease to reach $0.08 \mathrm{~g} / \mathrm{L}$ on day 8 . The decrease of the VFA concentration can be associated to the increase of the COD removal efficiency. From day 8 and till day 24, corresponding to an increase of the OLR from 0.65 to $3 \mathrm{~g}_{\mathrm{COD}} / \mathrm{L} . \mathrm{d}$, the VFA concentration was less than $0.2 \mathrm{~g} / \mathrm{L}$ and acetic acid was the main VFA produced. Such a low level explains the high COD removal efficiency of about 94\%. From day 25 and till the end of the start-up period, VFA 
concentration increased from 0.2 to $0.6 \mathrm{~g} / \mathrm{L}$ when the OLR was increased from 3.5 to 24.75 gCoD/L.d. During these 12 days the COD removal efficiency decreased slightly from $94 \%$ to $91 \%$ and we have noted a low accumulation of propionic acid in the effluent while the acetic acid remained the main VFA. Thus, the fast increase of the OLR did not disturb the methanogenic activity of the biofilm which remained metabolically stable over the whole start-up period and ensured a high COD removal efficiency.

[Figure 2 near here]

In comparison to previous studies investigating the start-up phase of up-flow anaerobic fixedbed reactors using plastic carriers $[8,10]$, the acclimation phase shorter when using GS as carrier support in addition to the higher removal efficiency in a shorter start-up period. In fact, Habouzit et al. [10] have used the same start-up strategy for the comparison of 4 different plastic carriers, and the start-up periods were ranged between 22 and 55 days. In comparison to their results, the performances obtained using GS were higher than polyethylene (PE) carriers and close to the most efficient supports investigated (polypropylene and polyvinyl chloride).This indicated that the GS can be used as an efficient carrier support in anaerobic fixed bed reactor as alternative to plastic supports.

\section{Inactivity period}

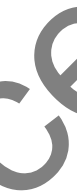

In order to simulate extreme seasonal variations in wine production, the reactor feeding with influent was stopped at the end of the first start-up period for three months. During the nonfeeding period, the biogas produced by the reactor was very low with only $12 \mathrm{~mL} / \mathrm{g}$ vs. The low biogas production corresponds to a low biodegradation of GS and could be explained by the high content of lignin in grape stalk that increase the longevity of the support in the reactor. Furthermore, GS has a low methanogenic potential with a BMP less than $100 \mathrm{~mL} / \mathrm{g}$ vs. [27] 


\section{Restart-up period}

After this period of inactivity, the reactor was fed again with influent and started-up faster than during the first phase. In fact, the reactor was started up with an initial OLR of 2 $\mathrm{g}_{\mathrm{COD}} / \mathrm{L} . \mathrm{d}\left(1.6 \mathrm{~g}_{\mathrm{COD}} / \mathrm{L}\right)$ which is three time higher than the OLR used to feed the reactor during the first phase. In addition, the OLR was increased faster till reaching 27 gCoD/L.d. Fig. 3 presents the OLR and the COD removal rate throughout the restart-up period. According to this figure, the reactor presented a high COD removal efficiency of $93 \%$ the first day of the restart-up without any phase for acclimation. This indicates that the biofilm was already acclimated to the influent and has conserved its activity even after a non-feeding period of 3 months. This could be due to the biochemical characteristios of the GS which are biodegradable supports and could be used as a slowly biodegradable carbon source for microorganisms. In fact, during the first start-up of the reactor, GS was used as carrier support for the development of the biofilm and as a second source of carbon for the microorganisms after ethanol, which was the main source of carbon. When the reactor feeding was stopped, GS remained as the only source of earbon for the biofilm to maintain its hydrolytic and methanogenic activities. In addition to the fast start-up, the reactor maintained a high COD removal efficiency during the first 9 days despite a daily increase of the OLR by $30 \%$ (which is twice the rate used during the first start-up). In fact, when increasing the OLR from 12.7 to $27 \mathrm{~g}_{\mathrm{COD}} / \mathrm{L} . \mathrm{d}$, the COD removal slightly decreased from $88 \%$ to $77 \%$. Compared to the first start-up phase, this could be attributed to the higher increase of OLR rate (30\% vs. $15 \%)$.

[Figure 3 near here]

At the end of the restart-up period, the OLR was kept constant (27 gCOD/L.d) for 4 days. During this stable phase, the COD removal efficiency increased from $77 \%$ to $82 \%$, which indicated reactor stability. 
Fig.4 presents the variation of VFA concentration throughout the restart-up period. During the three months of non-feeding period, there was no accumulation of the VFA. During the restart-up, VFA concentration increased according to the OLR. During the first 4 days, VFA were lower than $0.2 \mathrm{~g} / \mathrm{L}$ which illustrates the absence of acclimation phase. In fact, during the first start up, the microorganisms in the biofilm had to acclimate to use ethanol as the main substrate and GS as a second substrate. Thus, even when we stopped feeding the reactor with the influent for three months, the biofilm conserved its metabolic activity to degrade ethanol and to produce methane. However, during the restart-up, VFA accumulated faster than during the first start-up. Actually, VFA concentration increased from 0.2 to $1.4 \mathrm{~g} / \mathrm{L}$ at day 10 . This fast VFA accumulation caused a sharp decrease in COD removal efficiency and was due to the very strong increase of the OLR in only 10 days. However, at the end of the restart-up phase, when the OLR was maintained constant during 4 days, the VFA concentration decreased from 1.4 to $1 \mathrm{~g} / \mathrm{L}$, confirming the stability of the whole anaerobic digestion processes. 
According to these results, it is possible to conclude that the use of GS can present both economical and operational advantages. Firstly, GS can be used as low cost supports, widely available in winery industry, contrary to plastic support of high cost and the use of GS ensures a fast start-up of the reactor with high removal efficiency. Secondly, the lignocellulosic composition of these residues allows the biofilm to conserve its activity during the nonfeeding period by using this support as substrate; this anaerobic biofilm reactor can be operated under a sequential mode according to the seasonal variations in volume and concentration of winery wastewater. The proposed hybrid reactor thus permits to treat both winery effluents and grape stalks. The grape stalk will be renewed during the no-feeding period and the reactor could be operated as anaerobic solid reactor in batch mode. The grape stalk is renewable support and could be used as support and when it is degraded it could be used as organic amendment.

\section{Biogas production}

The methanogenic activity of the biofilm during the start-up and the restart-up was also investigated by following the methane production. Fig5. and Fig. 6 present the OLR and the methane yield throughout the start-up and the restart-up period, respectively. According to these results methane yields during both start-up and restart-up phases were similar. In fact, during these two phases, the methane yield was about $0.32 \mathrm{LCH} 4 / \mathrm{g}$ DCOdeg and decreased at the end of the start-up due to the high OLD supply to the reactor. However, the only difference between the start-up and the restart-up was observed during the first days. During the first start-up phase, the methane yield was higher (about $0.35 \mathrm{LCH}_{4} / \mathrm{g}$ DCOdeg) and then decreased, while during the restart up was, it was lower (about $0.25 \mathrm{LCH} 4 / \mathrm{g}$ DCOdeg) and then increased. In fact, when the reactor feeding with influent started, soluble matter released from the carrier support (GS) leads to an increase of the total soluble carbon available to the biofilm and as 
consequence, increases the quantity of the biogas produced, which is not the case when using plastic support. [9,28] However, during the inactivity period, the biofilm degraded biodegradable compounds from grape stalk and the total soluble carbon is only attributed to the COD of the influent. Moreover, the reduction of the methanogenic activity of the biofilm during the period of inactivity may also explain the slow production of biogaz during the first days of restart-up period.

As a consequence, in addition to reducing the costs, the use of grape stalk as carrier support displace to plastic support, allows the increase of the methane yield that could be produced from both winery wastewater and grape stalks.

[Figure 5 near here] [Figure 6 near here]

\section{Conclusions}

In order to reproduce the seasonal nature of winery industries, the present study evaluated the sequential operation of anaerobic biofilm reactor treating winery wastewater and using GS as a biofilm carrier to reduce the treatment costs. The results obtained showed that GS can be used as an efficient biofilm carrier support, and they can constitute an alternative to plastic carriers to reduce the treatment costs. Furthermore, using GS allowed a fast start-up of the reactor in only 40 days, with a high removal efficiency that reached $92 \%$ for an OLR of 25 gCOD/L.d. In addition to its low cost, the biochemical characteristics of GS could maintain a biofilm activity during the non-feeding period. This allowed biofilm to conserve its methanogenic activity and, as a consequence, digester was able to restart-up in only 15 days with COD removal efficiency higher than $80 \%$. Finally, this new low cost treatment process could be implemented on-site in wine factories because of the high treatment efficiency, the 
short start-up period as well as its ability to be carried out with successions of start-ups and shut-down operations, including non-feeding periods.

\section{References}

[1] Nataraj SK, Hosamani K M, Aminabhavi TM. Distillery wastewater treatment by the membrane based nanofiltration and reverse osmosis. Water Research. 2006; 40:2349-2356.

[2] Ruiz-Colmenero M, Bienes R, Marques MJ. Soil and water conservation dilemmas associated with the use of green cover in steep vineyards. Soil \& Tillage Research. $2011 ; 117: 211-223$.

[3] Brucculeri M, Bolzonella D, Battistoni P, Cecchi F.Treatment of mixed municipal and winery wastewaters in a conventional activated sludge process: a case study. Water Science and Technology. 2005; 51:89-98.

[4] Souza BS, Moreira FC, Dezotti MWC, Vilar VJP, Boaventura RAR. Application of biological oxidation and solar driven advanced oxidation processes to remediation of winery wastewater. Catalysis Today. 2013; 209:201-208.

[5] Petruccioli M, Duarte ,, Federici F. High-rate aerobic treatment of winery wastewater using bioreactors with free and immobilized activated sludge. Journal of Bioscience and Bioengineering. 2000; 90:381-386.

[6] Mosteo R, Sarasa J, Ormad M, Ovelleiro J. Sequential solar photo-Fentonbiologica system for the treatment of winery wastewaters. Journal of Agricultural and Food Chemistry. 2008; 56:7333-7338.

[7] Moletta R. Winery and distillery wastewater treatment by anaerobic digestion. Water Science and Technology; 2005; 51:137-14. 
[8] Ganesh R, Rajagopal R, Torrijos M, Thanikal JV, Ramanujam R. Anaerobic treatment of winery wastewater in fixed bed reactors. Bioprocess and Biosystems Engineering. 2010; 33:619-628.

[9] Cresson R, Escudié R, Steyer JP, Delgenès JP, Bernet N. Competition between planktonic and fixed microorganisms during the start-up of methanogenic biofilm reactors. Water Research. 2008; 42(3):792-800.

[10] Habouzit F, Hamelin J, Santa-Catalina G, Steyer JP, Bernet N. Biofilm development during the start-up period of anaerobic biofilm reactors: the biofilm Archaea community is highly dependent on the support material. Microbial Biotechnology. $2014 ; 7(3): 257-264$.

[11] Escudié R, Cresson R, Delgenès JP, Bernet N. Control of start-up and operation of anaerobic biofilm reactors: An overview of 15 years of research. Water research. $2011 ; 45: 1-10$

[12] Strong PJ, Burgess JE. Treatment methods for wine-related and distillery wastewaters: a review. Bioremediation Journal. 2008; 12:70-87.

[13] Mohana S, Acharya BK, Madamwar D. Distillery spent wash: treatment technologies and potential applications. Journal of Hazardous Materials. 2009; 163:12-25.

[14] Chatzilazarou A, Katsoyannos E, Gortzi O, Lalas S, Paraskevopoulos Y, Dourtoglou E. Removal of polyphenols from wine sludge using cloud point extraction. Journal of the Air and Waste Management Association. 2010; 60:454-459.

[15] Mosse K, Patti A, Christen E, Cavagnaro T. Review: Winery wastewater quality and treatment options in Australia. Australian Journal of Grape and Wine Research. $2011 ; 17: 111-122$. 
[16] Tarjányi-Szikora, S., Oláh, J., Makó, M., Palkó, G., Barkács, K., Záray, G., 2013. Comparison of different granular solids as biofilm carriers, Microchem. J. 107, 101-107.

[17] Andersson, J., Björnsson, L., 2002. Evaluation of straw as a biofilm carrier in the methanogenic stage of two-stage anaerobic digestion of crop residues. Bioresour. Technol. 85, 51-56.

[18] Mshandete, A.M., Björnsson, L., Kivaisi, A.K., Rubindamayugi, M.S.T., Mattiasson, B., 2008. Performance of biofilm carriers in anaerobic digestion of sisalleaf waste leachate. Elect. J. Biotechnol. 11 (1).

[19] Ping L, Brosse N, Sannigrahi P, Ragauskas A. Evaluation-of grape stalks as a bioresource. Industrial Crops and Products. 2011; 33:200-204.

[20] Deiana AC, Sardella MF, Silva H, Amaya A, Tancredi N. Use of grape stalk,a waste of the viticulture industry, to obtain activated carbon. Journal of Hazardous Materials. $2009 ; 172: 13-19$.

[21] Henze M, Harremoes P. Anaerobic treatment of waste water in fixed film reactors A litterature review Water Science and Technology.1983; 15: 1-101.

[22] Stronach SM, Rudd T, Lester J. Anaerobic digestion processes in industrial wastewater treatment. Biotechnology monographs. Springer-Verlag. 1986; 2: p. 184.

[23] Balaguer MD, Vicent MT, Paris JM. A comparison of different support materials in anaerobic fluidized bed reactors for the treatment of vinasse. Environmental Technology, 1997; 18 (5): 539-544.

[24] Habouzit F, Hamelin J, Santa-Catalina G, Steyer JP, Bernet N. Biofilm development during the start-up period of anaerobic biofilm reactors: the biofilm Archaea community is highly dependent on the support material. Microb Biotechnol. 2014 May;7(3):257-64 
[25] Barber WP, Stuckey DC. The influence of start-up strategies on the performance of an anaerobic baffled reactor. Environmental Technology. 1998; 19:489-501.

[26] APHA - American Public Health Association. Standard Methods for the Examination of Water and Wastewater. 1998; 20th ed.

[27] Dinuccio E, Balsari P, Gioelli F, Menardo S. Evaluation of the biogas productivity potential of some Italian agro-industrial biomasses. Bioresource Technology, 2010; 101: $3780-3783$

[28]Michaud S, Bernet, N, Buffière, P, Delgenès, JP. Use of the methane yield to understand the metabolic behavior of methanogenic biofilms. Process Biochemistry, 2005; 40 (8): 2751-2755. 


\section{Figure caption}

Fig.1 COD removal and OLR through the start-up period

Fig.2 Variation of VFA concentration during the start-up period

Fig.3 COD removal and OLR through the restart-up period

Fig.4 Variation of VFA during the restart-up period

Fig.5 Methane yield and OLD variation during the start-up period

Fig.6 Methane yield and OLD variation during the restart-up period

Table 1 Physico-chemical characteristics of grape stalks 


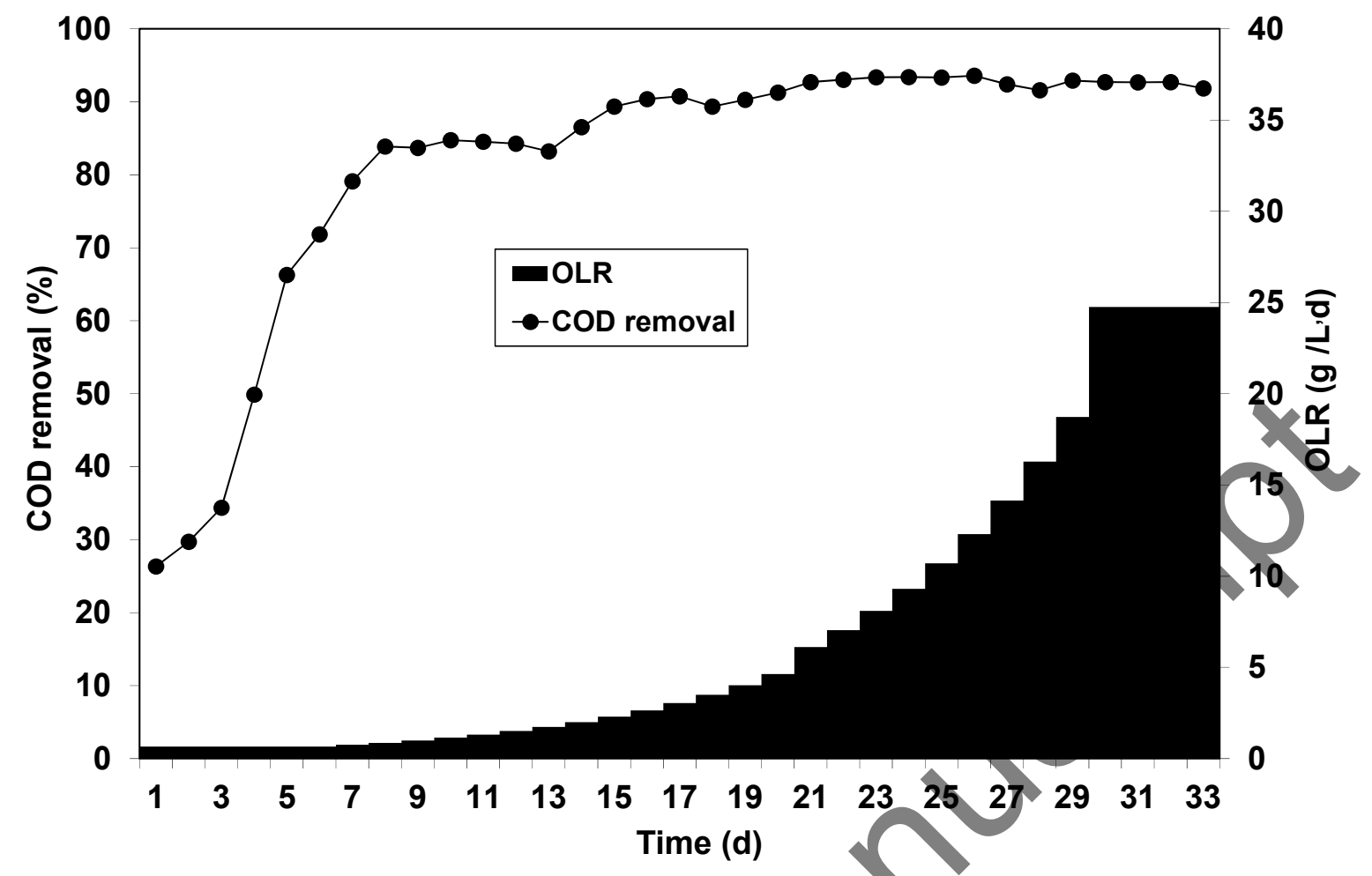




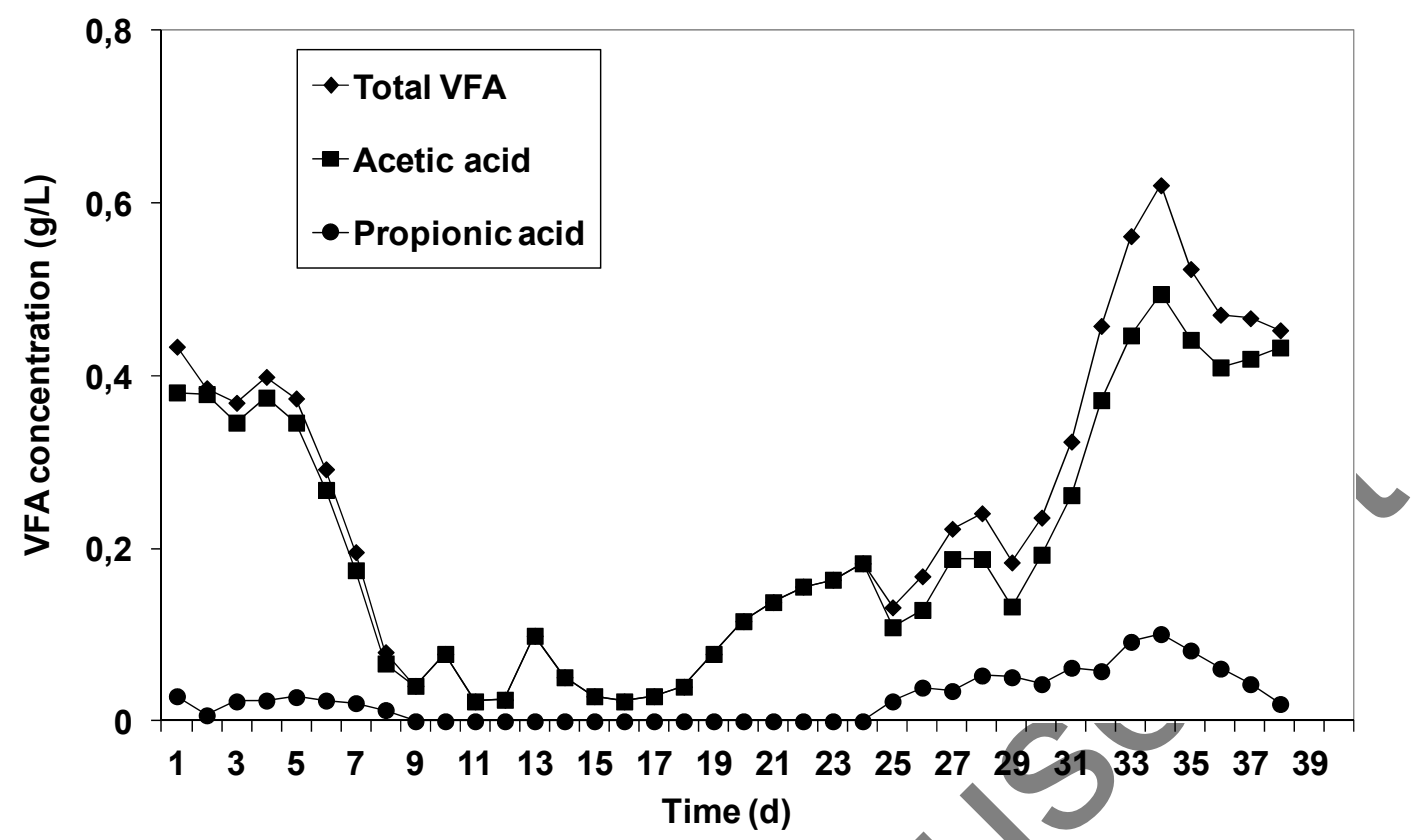




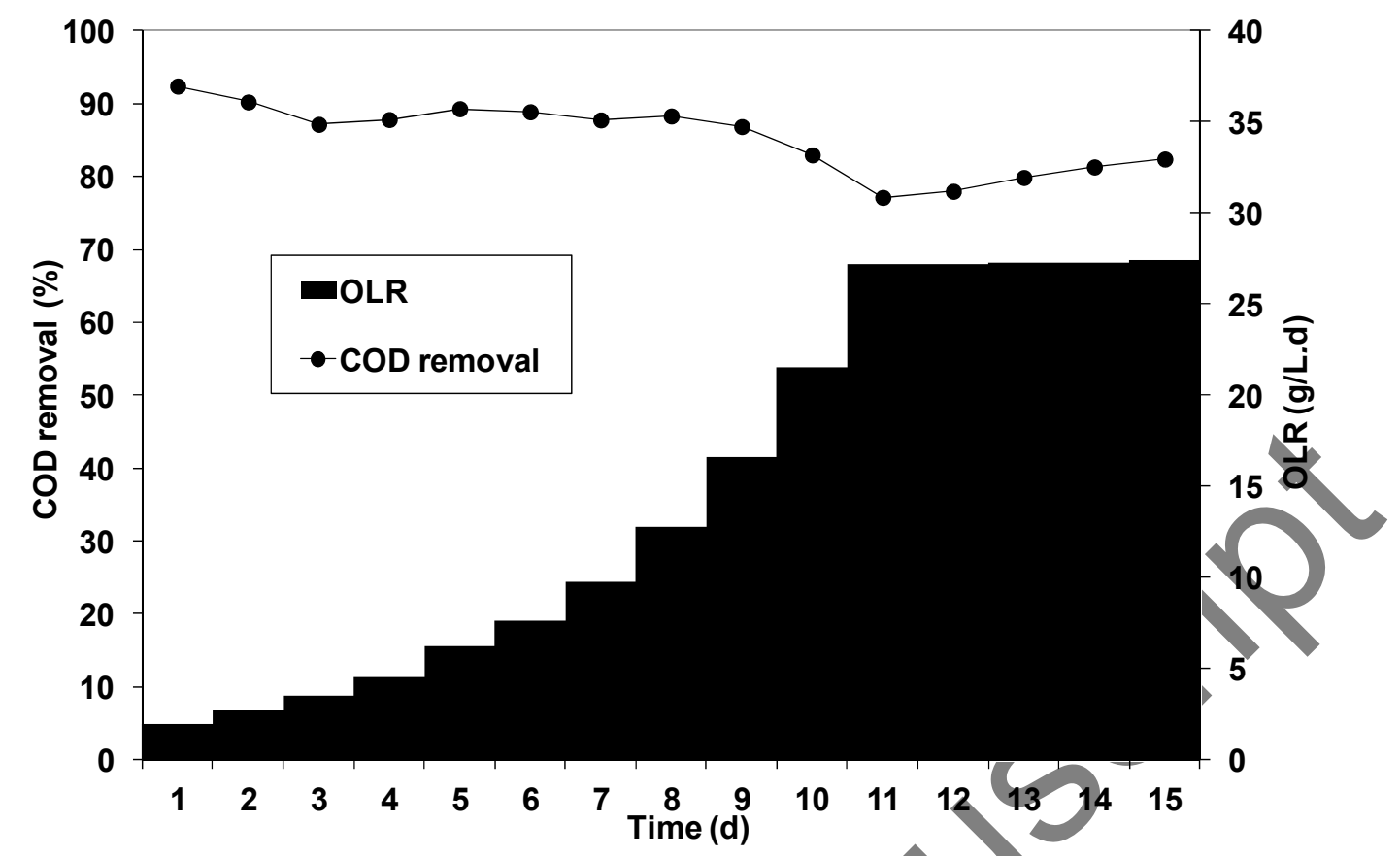




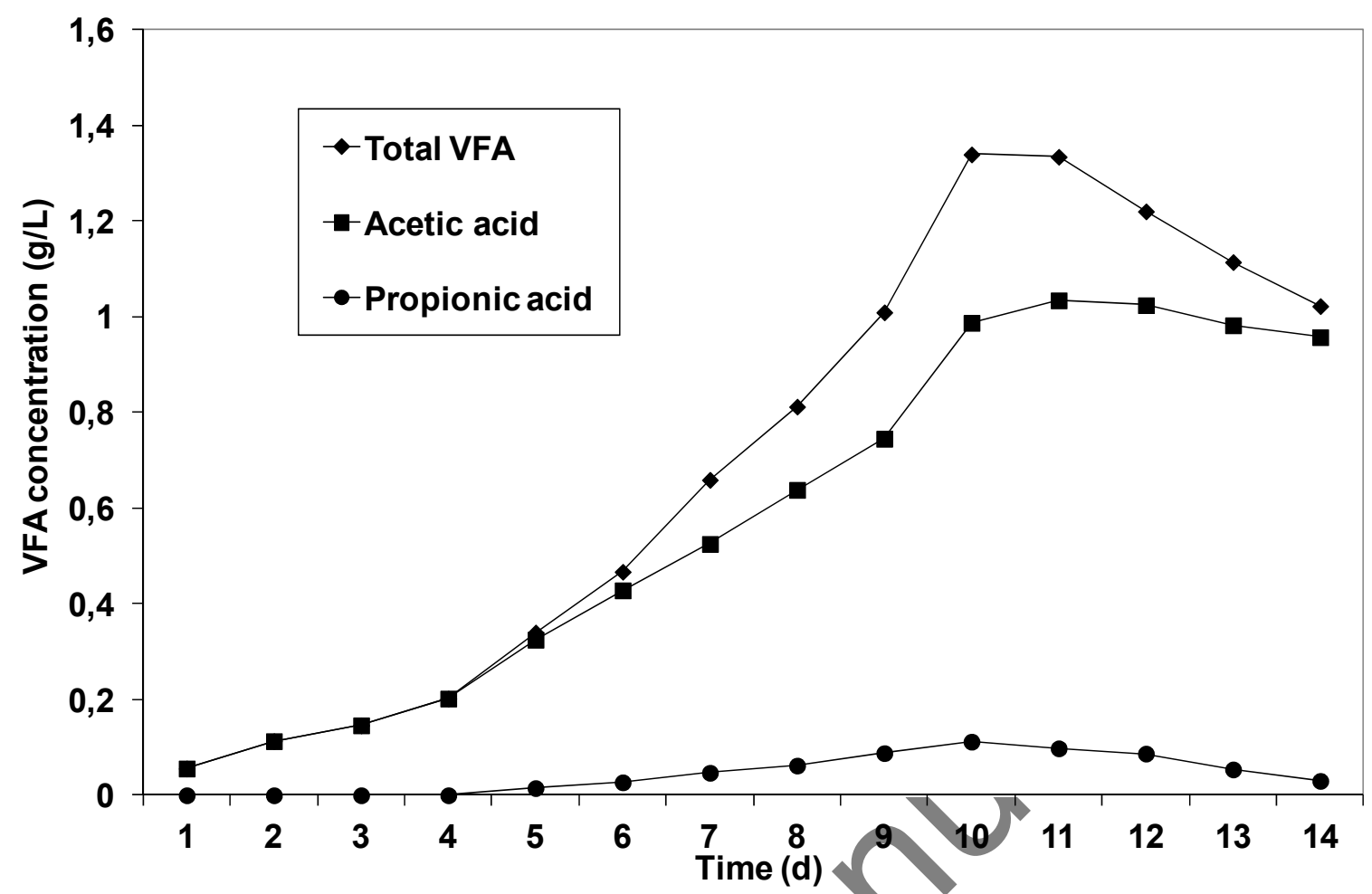




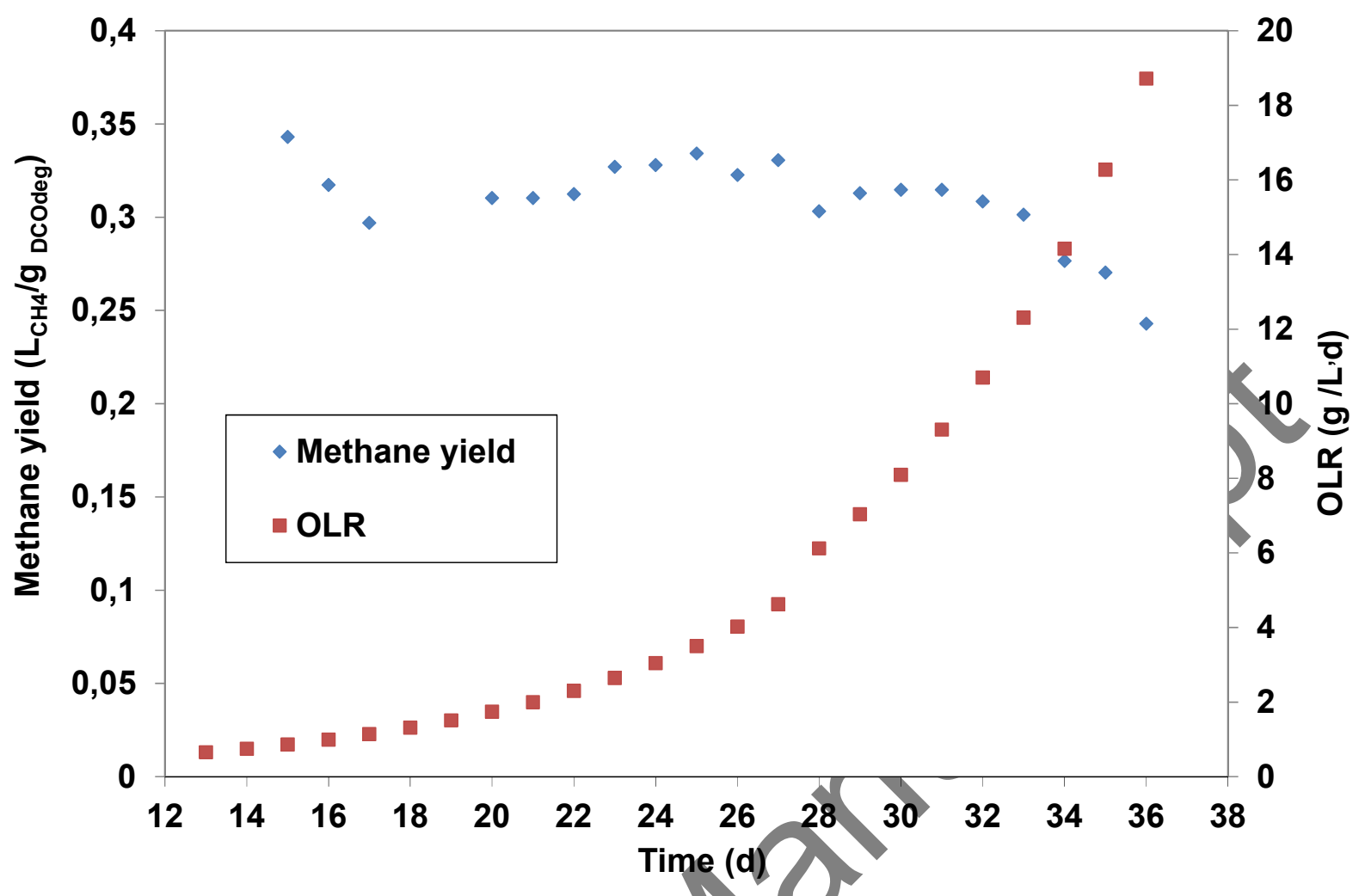




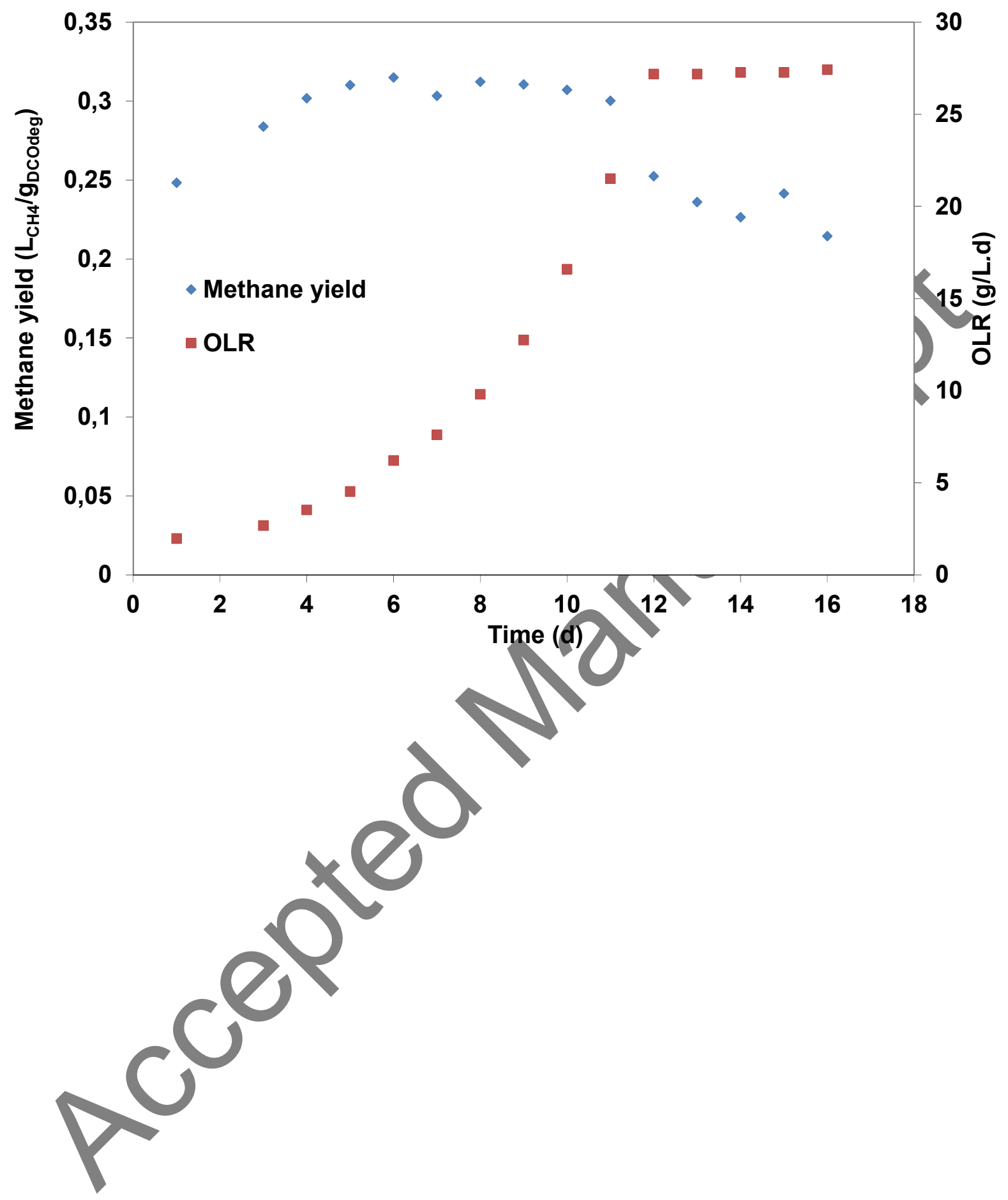




\begin{tabular}{|l|l|l|l|l|l|l|l|l|}
\hline Support & $\begin{array}{l}\text { TS } \\
(\%)\end{array}$ & $\begin{array}{l}\text { VS } \\
(\% T S)\end{array}$ & $\begin{array}{l}\text { Soluble } \\
\text { fraction } \\
(\% T S)\end{array}$ & $\begin{array}{l}\text { Hemicellulose } \\
(\% T S)\end{array}$ & $\begin{array}{l}\text { Cellulose } \\
(\% T S)\end{array}$ & $\begin{array}{l}\text { Lignin } \\
(\% T S)\end{array}$ & $\begin{array}{l}\text { Apparent } \\
\text { density } \\
\left(\mathrm{g} / \mathrm{cm}^{2}\right)\end{array}$ & $\begin{array}{l}\text { Pore } \\
\text { volume }\end{array}$ \\
\hline GS & 79 & 74 & 32.3 & 15 & 27.5 & 25.2 & 0.102 & 0.86 \\
\hline
\end{tabular}

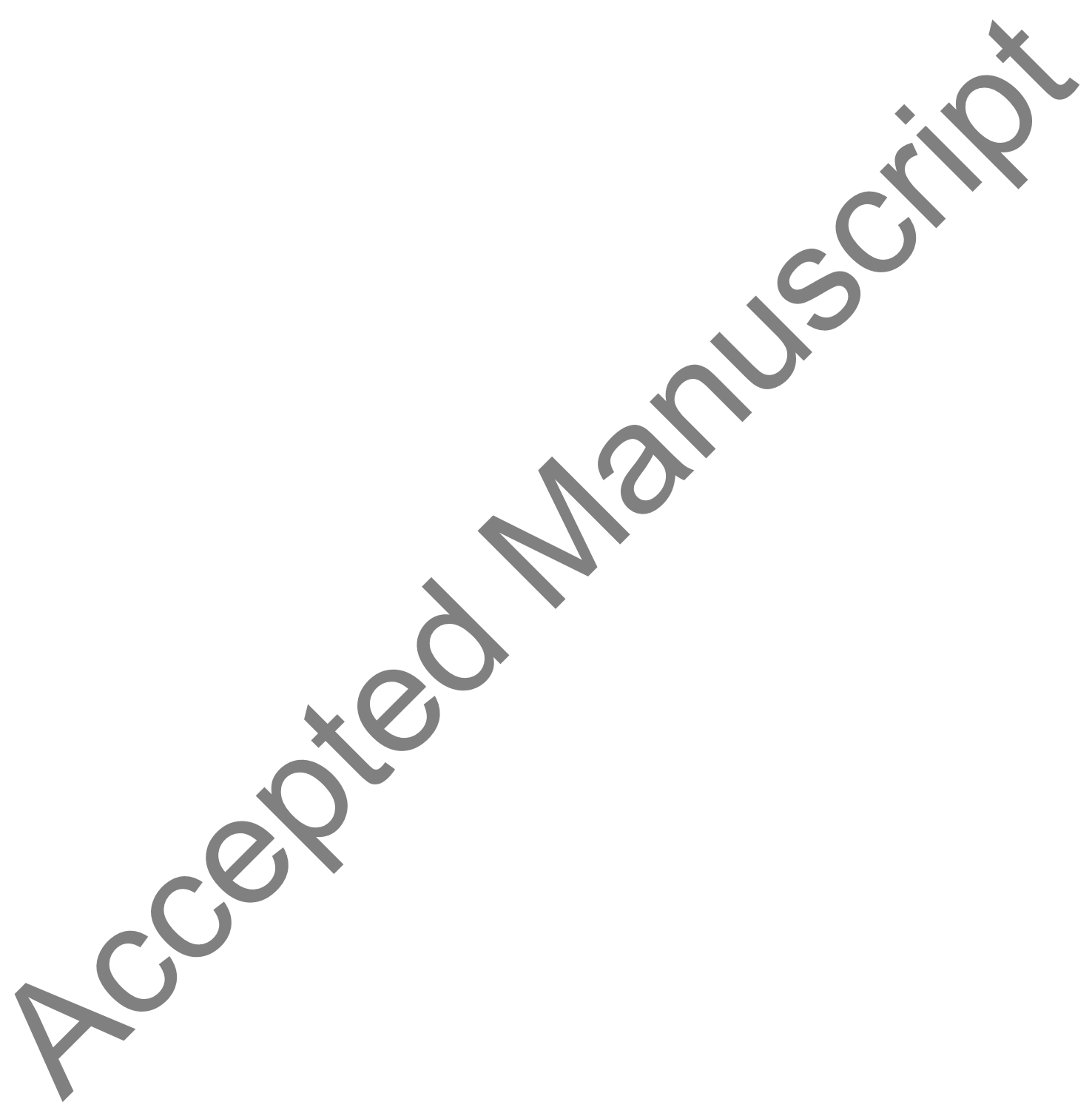

